\title{
AN APPROACH TO THE DESIGN OF FINANCIAL INSTRUMENTS FOR FOOD SYSTEM PROJECTS
}

Jacques Rogozinski

Nelly Ramírez Moncada 


\section{CONTENTS}

I. DESCRIPTION AND CONTEXT

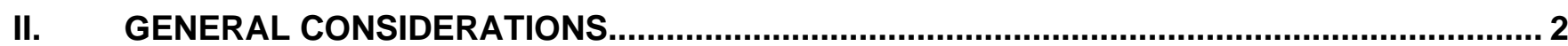

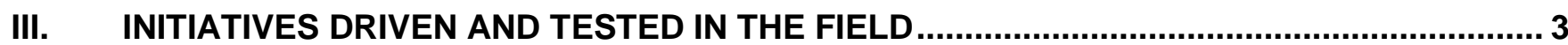

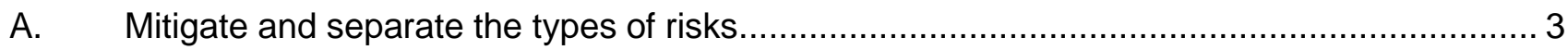

B. Leverage of large companies, the logic of chains. ...................................................... 4

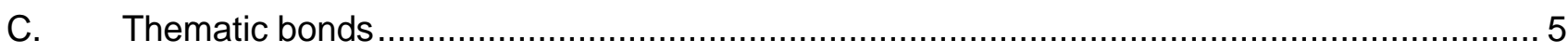

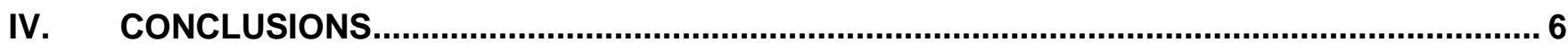

ABOUT THE AUTHORS 
This working paper is available in Spanish Version, LAC Working Paper number 19 ES.

This article collects a series of recommendations and experiences from multilateral banks, in particular from the Inter-American Investment Corporation in the period 2005-2013 for the financing of regional projects and the Development Bank in Mexico (2014-2018). Similarly, general considerations are provided for the design and implementation of innovative, flexible and balanced financing schemes between profitability and development in vulnerable sectors such as the food system.

\section{DESCRIPTION AND CONTEXT}

In recent years, great strides have been made in the innovation of financial systems for agriculture and environment projects. These include hybrid public and private financial mechanisms, financing schemes with risk leverage, as well as the structuring of bonds that seek to bridge the gap in the financing of projects on the part of commercial banks. In the current context of large-scale digital transformation combined with the great climate and food challenges in many regions, it is imperative to implement financing mechanisms for initiatives that are flexible, transparent but above all balanced, in terms of their local vocation (without losing out on that is a global perspective) and the search for profitability, which allows to progressively generate success stories in conjunction with the private sector, on a local, national and international scale. This starts from identifying and aligning with transparency the incentives of all the actors involved, be they public (local or regional) or private (international investors, local partners and farmers).

In this context, this article was written with the aim of providing ideas of financial mechanisms used in the past in other industries, but that share the logic of mitigating multiple types of risk and aligning incentives that industry projects also have. food.

According to the research "Financing healthy, sustainable and equitable food systems" by Eugenio Díaz-Bonilla, Johan Swinnen, and Rob Vos, in the financial world of food systems there are internal sources of financing (cash flow generated by the productive activities of the farmers and businesses operating throughout the food system) and external. This article will focus on the latter. "External" financing has four potential sources to consider: i) concessional official development assistance (ODA) and non-concessional loans from multilateral development banks (MDBs); ii) public sector budgets; iii) banking systems; and iv) capital markets.

\section{GENERAL CONSIDERATIONS}

Considering various development assistance initiatives and alternatives to encourage the private sector to participate in the financing of food systems, as well as contextual issues of vital importance, the following are some general ideas pertinent to the design of financing strategies:

1. Starting from the local to the global. Due to the exhaustive bureaucratic and legal processes involved in designing and implementing financial instruments, especially when it involves several actors, it may be tempting to promote instruments with multi-country application. However, it 
would be advisable to relax the rules that allow spaces for experimentation and sandbox-type implementation (well-known now in the FinTech world). From this logic, all initiatives should have as a starting point pilot programs, small-scale financing programs, with an innovative approach, but with clear premises and assumptions of validation and research that allow later to design to scale to other regions / localities that have similar characteristics.

2. Do not design mechanisms for static contexts. A great learning last year is the constant change to which all institutions and companies must adapt permanently. This also implies designing instruments that allow real-time learning of their implementation and adjusting on the fly. The idea is to bring the agile logic that has been successful in the world of technology, to the world of finance, especially to that of international finance.

3. Collaboration and integration with Agro-FinTech, AgriFood Tech and AgroTech. As part of the technological revolution process that we are experiencing, a large number of local, regional and global initiatives have emerged with a focus on Agro-Tech and Agro-FinTech. By some estimates, smart agriculture could have a market value of $\$ 23$ billion by 2022. Even though a lot of venture capital has been mobilized to finance some of these initiatives and companies in developed countries, transfer financing should be considered. of capacities, opening of operations and collaboration of these companies (ie Augmenta, DouxMatok, Hectare Agritech, Trimble, Syngenta, Indigo, etc.) with regions and developing countries where there could be complementarity and a work scheme combined with traditional systems. These technology companies are innovating with such a level of specificity and targeting (land management, pesticide, food production, insurance, microfinance, value chain management, fintech, etc.) which allows a much more concrete analysis of their potential participation in an initiative. The role of international and / or multilateral organizations could be to generate trust, structure transfer mechanisms and align incentives for all parties.

4. Culture matters. An important factor when designing a financial instrument is the identification and segmentation of the target market. On occasions, multilateral or regional financial organizations, being far from the operation in the field, can ignore cultural and political elements that impact the possibility of success or failure of an initiative and promote projects with a generalist and standardization perspective. A cultural and political view could mitigate some of these risks from its initial design, seeking to adapt to local contexts instead of the other way around and, above all, to promote a design that considers specificities, localisms and differentiated needs of certain populations, with a logic modular and flexible to allow these adaptations and continuous iteration.

\section{INITIATIVES DRIVEN AND TESTED IN THE FIELD}

\section{A. Mitigate and separate the types of risks}

When designing financing schemes for development, the challenge to attract capital is the search for profitability and the balance between risk and return. In Latin America, for example, in addition to project risk, country risk must be considered. In projects, when considering business or private accounting, 
country risk increases the level of reserves that must be accounted for and this means that at the end of the year the level that was recorded for reserves impacts profit.

The other challenge is currency risk. When these two types of risks are combined in any project (not only in an agricultural project) its viability becomes more complex, because the private sector requests compensation for the risk with greater utility. This generates that it is out of the possibilities of what a project can achieve. For example, if a country has a high risk as a country and a reserve of $15 \%$ must be counted from the outset and to that add the project risk reserve, then it may be the case that before dispensing, for every dollar it is necessary to reserve 19 cents, which would go against earnings for the year.

One way to mitigate this, taking up the lessons learned from the Inter-American Investment Corporation in the period 2005-2013, is for the part that corresponds to country risk to be somehow immersed or recorded in the balance sheet of another institution. For example, an institution such as the Food and Agriculture Organization of the United Nations (FAO) could manage a trust that takes on this role.

The country risk in most cases never materializes, therefore, the challenge is to separate the country risk so that it is registered in a balance different from that of the project. In this scenario, the private fund - taking up the previous example - would no longer have to reserve $19 \%$ but only $4 \%$ that would correspond to the risk of the project. In this scheme, the possibility of receiving private financing is increased. In the case of exchange risk (especially for projects with capital from abroad) this could be reduced through a mechanism established by the host country of these investments, which through its local financial system designs it specifically for the food sector.

Financing schemes are complex even when it comes to development institutions, such as what was once the Inter-American Investment Corporation, even there there is a balance or a very narrow line because projects are always required to have a minimum profitability and this profitability becomes more complex when a project must account for a high percentage of risk from its design.

In conclusion, it is recommended to separate the different types of risks, project risk, country risk and exchange risk and establish strategies to mitigate and disconnect each one from the main project.

\section{B. Leverage of large companies, the logic of chains.}

Another possible strategy for small agricultural producers is to use a large company to finance projects with local farmers. At the Inter-American Investment Corporation, we promoted projects in Mexico with large multinational companies in which, through a chain logic (with their suppliers), they were able to promote small local companies that received financing through the large company.

In the old Corporation (today IDB Invest) these large companies were financed and they identified small producers in their value chain, who had a positive relationship history of years and the company knew that they were reliable. In this scheme, the producer was offered, for example, the purchase of more dairy cows of cattle so that he had a higher production. The money that came in this case from a multilateral company -which was the Inter-American Investment Corporation- went to the large company and this gave it to the small producer; With that money, the small producer could buy 10 or 15 additional cows and therefore each time, every week or every two weeks that they came for the milk of that producer, they had more liters of milk and their income improved. 
Now, how did that producer pay that credit? The credit was paid because in each delivery of milk the large company withheld a small payment to pay off his credit. The same, for example, with carriers, you could be lent for improvements in your transportation system. For example, a refrigeration system for the trucks with which he went to all the rancherías to collect that milk, an investment in a modern truck allowed him to improve its quality and service.

The company collected the money and put it in a trust and once every three months it returned the money to the Corporation. The scheme worked because in many cases these large companies already have a supply system with some stability and durability.

Through this mechanism it was possible to finance small producers who otherwise would not have had access to financing. In this scheme, everyone benefited. The large company benefited because it received its product or service on time and in better condition and the small producers could invest and improve their income. A general description of this initiative can be seen in Box 1 (of the annual report of the former Inter-American Investment Corporation for 2003, pages 36-37) with the specific case of Nestlé in Mexico in conjunction with a local financial institution.

\section{Box 1: Nestlé in Mexico}

Program: up to US \$10 million. Subloans: US \$5,000 to US \$ 50,000. Project cost: US \$15 million.

This program aimed at financing small agricultural companies supplying milk to Nestlé México S.A. de C.V. It was structured in conjunction with this company and a local financial entity, who are in charge of the operational part. Nestlé will serve as program administrator, collection and identification agent and member of the evaluation committee. The local financial entity will act as trustee, and all IIC loans to small agricultural companies will be channeled through this trust. Once the loans have been arranged and approved, the IIC assumes the risk directly with each agricultural company that benefits from the financing. The initial amount of the pilot program is US $\$ 10$ million, while the subloans will not exceed US $\$ 50,000$ per company. Through the program, the IIC is expected to provide direct financing to an estimated 300-600 small dairy companies throughout Mexico. The program will last for ten years, providing long-term sustainability and continuous support to small producers. It is conservatively estimated that the program will generate an average of at least two jobs per loan / farmer in a sector characterized by intensive use of labor. In addition, the program will save foreign exchange expenses of an annual value of US \$10 million to US \$15 million, and will contribute between US \$ 25 million and US \$ 35 million annually to Mexico's gross domestic product

\section{Thematic bonds}

Another important instrument for financing the transformation of the region's agri-food systems are thematic bonds. For example, at Nacional Financiera (NAFIN) of Mexico, in September 2016 the first green bond (500 million dollars over five years) was issued by a development bank in Latin America and the first green bond in Latin America that had the international Climate Bond Certification issued by the Climate Bond Standard Board. The resources were entirely dedicated to financing renewable energy projects. 
Likewise, NAFIN issued on July 21, 2017 the first social bond listed on the Mexican Stock Exchange that has a second opinion. The issue was for 4,000 million pesos at an adjustable rate. The resources have been used to finance programs with social goals in Mexico such as:

- Improved access to education, vocational training, financing and financial services for low-income and marginalized populations, including young entrepreneurs and students.

- Generation of employment through microfinance and financing directed at micro, small and medium enterprises (MIPYMES).

- Socio-economic development and empowerment of women by granting loans to women entrepreneurs who want to expand their businesses.

- Improvement of cost savings in the families' economy, through the efficient use of resources for low-income households, financing the installation of high-efficiency products and technologies.

- Support for the economic recovery of individuals and micro, small and medium enterprises (MSMEs) affected by natural disasters.

The NAFIN Social Bond complies with the 2017 Social Bond Principles of the International Capital Market Association ("ICMA"), and additionally contributes to the Sustainable Development Goals (SDGs) of the United Nations. United, in the fight against poverty, inclusive education, gender equality, decent employment and sustained, inclusive and sustainable economic growth.

The issuance of these bonds served to emphasize the commitment that a development bank can have with the social and environmental sector, motivating other local issuers to enter that market. In its structuring and design, one of the key factors was that prior to its issuance there was a portfolio of projects identified and analyzed, thus making their management faster and more efficient.

\section{CONCLUSIONS}

These ideas that were successfully implemented in different Latin American countries share common characteristics;

1. They consider incentives in a win-win logic for the public and private sectors;

2. They seek a balance between profitability, risk and the need to promote vulnerable sectors;

3. The participation of a multilateral organization as a catalyst for resources, but also as an entity that generates trust and cohesion between the parties (governmental and private) and as a mechanism for absorbing risks that are more general than those specific to the project.

Together with the recommendations and ideas presented at the beginning of this article, inputs and elements that could add to current efforts to design financial instruments for the food sector are considered. 


\section{ABOUT THE AUTHORS}

Jacques Rogozinski is an economist with a long and distinguished career in Mexico and internationally. He worked at the Secretariat of Finance and Public Credit (1989 - 1992); later he was General Director of the National Bank of Public Works (1992-1994), and General Director of the National Development Trust for Tourism Development (Fonatur) (1994-1995) in Mexico. After that he was a high-level official both in the Inter - American Development Bank and the Inter - American Investment Corporation where he spent more than 15 years (1996 - 2012) as Advisor on private sector matters, Deputy general manager of the Inter-American Investment Corporation (1999), and General manager of the Inter-American Investment Corporation (2000-2012). Subsequently, he returned to Mexico as General Director of the Development Banking Institution (NAFINSA) (2012 - 2018). During this period, he was also President of the Board of Directors of the Latin American Association of Development Financing Institutions.

Nelly Ramírez Moncada, is an international development professional and intrapreneur with over a decade of experience in developing and emerging economies in the public and private sector in areas of social, financial, and digital inclusion. Professor at the National Autonomous University in Mexico and at the International School of Finance (Afi). Currently Vice President and Head of Advanced Digital Services at Fundación Capital, a global social enterprise working to promote economic citizenship globally and at scale with technology. Mentor for Tech based social startups and currently a PhD candidate in Public Administration, holds an MA in Political Science, a Law Degree, and a BA in International Relations.

\section{INTERNATIONAL FOOD POLICY RESEARCH INSTITUTE

